\title{
Ureteroscopy in Children-A Single Centre Study from a Developing Country
}

\author{
Nadeem Iqbal ${ }^{{ }^{*}}$, Nizam Farid Chishti ${ }^{1}$, Sajid Iqbal ${ }^{2}$, Syed Imtiaz Ali ${ }^{3}$, Amgad Farouk $^{3}$, Ijaz \\ Hussain ${ }^{4}$, Usama Bin saif ${ }^{4}$, Ahsan Nazar ${ }^{4}$, Saeed Akhter ${ }^{4}$ \\ ${ }^{I}$ Department of Urology and Kidney Transplant, Pakistan Kidney and Liver Institute \\ ${ }^{2}$ Department of Rehabilitation, Pakistan Navy PNS Hospital, Karachi \\ ${ }^{3}$ Department of Urology, Medcare Hospital Jumaira, Dubai \\ ${ }^{4}$ Department of Urology and Kidney Transplant. Pakistan Kidney Institute, Shifa International Hospital \\ Islamabad
}

*Corresponding Author: Nadeem Iqbal, Department of Urology and Kidney Transplant, Pakistan Kidney and Liver Institute, E-mail: dr_nadeemiqbal84@yahoo.com

\begin{abstract}
:
Purpose: To determine efficacy and safety of initial experience of ureter stone management by ureteroscopy in pediatric patients in a single center in a developing country. As pediatric urology is lacking in expertise in such countries so the aim of study was to share outcomes in the initial experience with pediatric ureteroscopy in northern side of Pakistan.
\end{abstract}

Methods: Retrospective analysis of the data was done in pediatric patients who underwent ureteroscopic intervention for ureter stone management at shifa international hospital from 2011 till 2018.Data regarding mean ureteric stone location, stone size, success rates and complications was collected by urology residents and recorded on specified proforma. Data was analyzed on SPSS version 16.

Results: Total of 67 children were followed after ureteroscopic procedure for ureter stone treatment. Their mean age was $8.51 \pm 4.73$ years. Male children comprised majority of patients in our study. Mean stone size was $10.03 \pm 5.97 \mathrm{~mm}$. Mean procedure time was $54.12 \pm 13.91$ minutes. Overall stone free rate after attempting first URS procedure was seen in $61 / 67$ of patients $(91.01 \%)$ in this study. Urosepsis was seen in $5.4 \%$ children. Rests of complications were of minor grades.

Conclusion: Ureteroscopy can be effectively and safely adopted in new centers of pediatric endourology with minimal morbidity and satisfactory success rates.

Keywords: Ureter, urolithiasis, children, stone free.

\section{INTRODUCTION}

Urolithiasis in pediatric age group is comparatively rare having an overall incidence of almost less than 3\% [1]. Pakistan has high prevalence rate of renal stones reaching up to $10 \%$ [2]. Among various factors infection is supposed to be one of the leadingcausative factor for urolithiasis in pediatric age group [3].Proper management of urolithiasis depends on location and size and of the stone, age of the patient and the urinary tract anatomy. During the last few decades, a wide range of modalities such as extracorporeal shock wave lithotripsy (ESWL), percutaneous nephrolithotomy (PCNL), ureterorenoscopy (URS), open and laparoscopic surgery has been available for treating adult stone diseases[4,5]. Most of these available techniques evolved in adult population and were adapted for use in children after doing appropriate modifications. Applying one or a combination of these modalities in carefully selected patient can help in successful management stones even in pediatric population.

As mentioned already, in past, many of such cases of urolithiasis in children used to be managed by open surgical method. However, with the introduction of miniaturization of the endoscopic instruments, it is now easier to treat ureteric stones by using the ureteroscopes $[5,6$, 7]. Introduction of Ureteroscopes has made the ureteric stone procedure less invasive not only in adults but in children as well. 
However, it is still not fully adopted in many parts of the world due to lack of training, experts in field and the required facilities. This being the reason it's still challenging to use this modality for treating paediatric ureteric stones. As these procedures have not been adopted in pediatrics as commonly as they have been used in adult age patients, so literature regarding pediatric ureteroscopy is found less frequently [7-10]. We wanted to share our initial experience of ureter stone management by ureteroscopy in pediatric patients presenting to shifa international hospital, Islamabad. This was the initial experience in northern side of Pakistan.

\section{Material AND MethodS}

All children who underwent surgical treatment for ureteric stones at shifa international hospital, Islamabad between 2011 till 2018 were included in this study. It was a retrospective study that was taken prospectively later. Children who had symptomatic stones of size greater than $5 \mathrm{~mm}$ in ureter were included in this study protocol. Data regarding mean ureteric stone location, stone size, success rates and complications was collected by urology residents and recorded on specified proforma. Data was analyzed on SPSS version 16. To proceed with ureteroscopy was made in cases where the ureteric stone was caused symptomatic pain, dilation of upper urinary tract or ESWL refusal by parents of the children. Children with anatomic abnormalities of ureter (stricture ureter), positive urine cultures, and bleeding disorders were not included in the study.

Preoperatively all children had to undergo blood investigations including complete blood picture, Urea and electrolytes, urine culture and sensitivity test, ultrasound KUB (kidney, ureter and bladder), intravenous urography (IVU) / CT (computed tomography) scan abdomen and pelvis. Ureteroscope (URS) was done in all children under general anesthesia. Lithotomy position was made and a wire was passed through the ureteric orifice under camera vision of cystoscope. Three fr open end ureteric catheter was passed over glide the wire under guidance offluoroscopic imaging.

Retrograde pyeloureterogram (RPUG) was done after injecting contrast via open end catheter (3 fr) was passed into ureter under fluoroscopic guidance to delineate anatomy of ureter and identifying the stone location (filling defect).URS $(7 / 9$ fr) was taken up to the stone and a pneumatic lithoclast was used to break it into small pieces. Larger fragments were removed by using dormia basket. After breaking and clearing the stone, JJ stent of $3.6 \mathrm{fr} / 4.7 \mathrm{fr}$ was passed at end of procedure. JJ stent was removed after 4 weeks of the URS procedure.

Stone clearance was defined to be achieved in case of insignificant stone residuals (size less than $4 \mathrm{~mm}$ identified on X-ray KUB or ultrasound KUB). All the patients were analyzedfor variables such as gender, age, size of stone and location, operative time, hospital stay, and perioperative complications and stone clearance. Children were followed after URS to see for ureteric stricture and other complications. Data collection was done after chart review. SPSS version 16 was utilized for data analysis. Mean \pm SD was used to denote variables such asstone size, age, mean operative time in minutes, and hospital stay. Frequency percentage was used to denote variables like presenting symptoms, gender, site, complications and stone clearance.

\section{RESUltS}

Total of 67 children were followed after ureteroscopic procedure for ureter stone treatment. Their mean age was $8.51 \pm 4.73$ years. Male children comprised majority of patients in our study. Mean stone size was $10.03 \pm 5.97$ $\mathrm{mm}$. Majority of the stones were located in proximal ureter followed by mid and distal ureteric stones (Table I). Stones on the left side were more as compared to the right sided stones.

Table1. Demographics of patients

\begin{tabular}{|l|l|}
\hline \multicolumn{1}{|c|}{ Children number } & \multicolumn{1}{c|}{$\mathbf{6 7}$} \\
\hline Male & $47(70.1 \%)$ \\
\hline Female & $20(29.9 \%)$ \\
\hline Mean age (years) & $8.51 \pm 4.73$ years. \\
\hline Mean stone size (mm) & $10.03 \pm 5.97 \mathrm{~mm}$ \\
\hline Left Sided stone & $41(61.1 \%)$ \\
\hline Right Sided stone & $26(39.9 \%)$ \\
\hline Proximal ureter stone & $39(58.2 \%)$ \\
\hline Mid ureter stone & $11(16.4 \%)$ \\
\hline Distal ureter stone & $17(25.3 \%)$ \\
\hline
\end{tabular}


Overall stone free rate after attempting first URS procedure was seen in 61/67of patients $(91.01 \%)$ in this study. Stone clearance in upper ureter was lesser as compared to those in mid and distal ureter. The stone fragments leftover after ureteroscopy were removed on relook URS after 1 month. On relook ureteroscopy we achieved $100 \%$ stone clearance in cases where stone clearance couldn't be achieved in first attempt. There was no ureter avulsion injury or major laceration during surgery. On long-term follow up of one year we didn't see any case of ureter stricture in these children.

Mean procedure time was $54.12 \pm 13.91$ minutes. Procedure time was more in impacted and larger stones as compared to those with the non-impacted and smaller stones. Impacted stones made ureteroscopic manipulation difficult due to local edema due to inflammatory changes in ureter wall secondary to the stone. Many of these children were sent home after one day of hospital stay (Table II). Those with upper ureter stones underwent more relook ureteroscopy as compared to the patients with mild and distal ureter stones.

Table2. Procedure outcomes and complications

\begin{tabular}{|c|}
\hline Variables \\
\hline Stone free rate \\
\hline Mean operative time \\
\hline Hospital stay \\
\hline Double $\mathbf{J}$ stent used \\
\hline Transient hematuria \\
\hline Ureter abrasion \\
\hline Ureter avulsion \\
\hline Ureter stricture \\
\hline Urosepsis \\
\hline
\end{tabular}

\section{DISCUSSION}

Urolithiasis has been one of the important causes of morbidity in human beings. Pakistan is located in the geographic belt with high incidence of stone disease. [11, 12] Alot of work has been done, in last 3 decades, regarding better and effective surgical management of urolithiasis [13]. Nowadays, approach for treatment of these stones has progressed from open surgical techniques to minimally invasive endourological management.

New modalities includingESWL(extracorporeal shock wave lithotripsy), PCNL (percutaneous nephrolithotomy), and URS (ureteroscopy) have been widely adopted in adult population in many centers across the globe however there is paucity of such experiences in pediatric population due to lack of instruments, facilities
There were 9/67(13.3\%) patients with grade 1 complication (transient hematuria, vomiting and fever) according to modified Clavien classification.

Urosepsis (grade $4 \mathrm{~b}$ complication) was seen in 4/67 (5.4\%) patients. Children having prolonged history of stone in ureter, impacted stones and previous urinary tract infections (UTI) were more prone to urosepsis development in this study as 3 of the children had episodes of UTI in past history. They were treated in accordance with urine culture reports by administering intravenous antibiotics and were successfully resolved. Even though it was our initial experience with minimal invasive ureteroscopic intervention at our center, however, it's pertinent to note here that ureteric mucosal injury (grade 1 complication) was seen in 4 patients our study. Furthermore, no case of ureteric stricture was seen in any child on follow-up.

There was one case of ureteric perforation (grade 3b complication) however that resolved successfully on follow up with management by keeping double $\mathrm{J}$ stent in ureter for 5 weeks. No other major morbidity was seen in our cases (Table II)
$61 / 67(91.01 \%)$

$54.12 \pm 13.91$ minutes

$1.27 \pm 0.86$ days

$49 / 67(73.1 \%)$

$8(11.9 \%)$

$6(8.9 \%)$

None $(0 \%)$

None $(0 \%)$

$4(5.4 \%)$

and expertise in many countries, especially the poor countries of world.

Modern surgical techniques for treating urolithiasis have resulted in lesser rates of morbidities that were associated with open surgical methods. In addition, efficacy rates have also sharply increased with the adoption of newer modalities [14].Extracorporeal shock wave lithotripsy is known to be gold standard for treatment of renal and ureteral stones in adults for the last many years. They are continuing to be popular clinical practice. However in pediatrics studies regarding ureteroscopy (URS) and shock wave lithotripsy have not been frequently done [15].

Both SWL and URS are considered to be better options for treating smaller stones, but there is one main advantage of URS over that of ESWL, 
as in URS intraoperative examination of the ureter and renal collecting system is possible. One of the concerns in children undergoing SWL is the fear of possibility of procedure failure or need for repeat SWL session if stone is not completely cleared in first session of SWL [16]. Ureteric stone disease poses challenge to the treating urologist in children due to fear of complications while inserting a semi rigid ureteroscope into a relatively thin ureter in children [17].

In USA, a recent trend of change has been observed regarding preference for the use of URS while treating ureter stones. According to their findings, it was noted that more children required additional sessions of SWL after initial shock wave lithotripsy.Keeping in view this phenomenon more children are likely to undergo URS as initial treatment modality for management of ureteric stones [13]. In modern countries URS has now become a safer procedure in pediatric population as well $[17,18]$. However in developing counties it's still in nascent stages and is not used widespread. In a study by jalbani et al. nineteen children were studied with ureter stones. They had with mean age of 7 years while average stone size was approximately $1 \mathrm{~cm}$. Their stone free rate was $95 \%$. However they didn't do procedure in locations other than distal ureter stones [7]. Our success rate was $91.01 \%$.We had included proximal and mid ureter stones.

Van savage et al concluded in review of distal ureteric stones in pediatric patients that calculi of size more than $4 \mathrm{~mm}$ were less likely to pass spontaneously and as such would need invasive intervention [18]. In our series mean stone size was $10.03 \pm 5.97 \mathrm{~mm}$. URS is a safe procedure in developed countries having acceptable stone free rates in the pediatric population. However factors such as multiple stones, Younger age, and proximal location predispose to failure. Furthermore, proximal ureter location has been found to be the main reason of complication in ureteroscopy [19].

Therefore, semi-rigid ureteroscopy should not be the first choice in the treatment of proximal ureteral stones, and alternative methods should be preferred, if available.

There are some concerns regarding possible development of stricture and vesicoureteric reflux (VUR) after ureterorenoscopy in children. Schuster et al concluded in a literature review of URS procedures in children that less than $1 \%$ of patients developed stricture and less than $4 \%$ had low grade vesicoureteric reflux [20]. In our series however we didn't see any case of stricture ureter or VUR. To avoid such complications it's necessary to place dj stent in ureter if there is difficulty in negotiating URS into the ureter. At times, more than one type of modality or a combination of surgical modalities may be needed to achieve the treatment goal in pediatric stone disease. Complications of ureteroscopy are common in younger children and adequate expertise and experience may avert these complications in younger children $[21,22]$.

\section{CONCLUSION}

Ureteroscopy can be effectively and safely adopted in new centers of pediatric and urology for treatment of ureter stones with minimal morbidity and satisfactory success rates.

\section{REFERENCES}

[1] Schwarz RD, Dwyer NT. Pediatric kidney stones: Long-term outcomes. Urology. 2006; 67:812-6.

[2] Reddy PP, Minevich E. Renal calculus disease. In: Docimo SG, Canning DA, KhouryAE, editors. Clinical pediatric urology. 5th ed. London:Informa Healthcare;2007: 387-98.

[3] Iqbal N, Muhammad S, Zafar W, Tashfeen R, Faiz J, Hasan A, Hussain I, Akhter S. StoneFree-Rate After Extracorporeal Shockwave Lithotripsy in the Management of Pediatric Renal Stones in Lower Pole and Other Locations - A Comparative Study. J Coll Physicians Surg Pak. 2016 ;26:908-911.

[4] Straub M, Gschwend J, Zorn C. Pediatric urolithiasis: The current surgical management. PediatrNephrol. 2010;25:1239-44.

[5] Hussein NS, Gohar MR. Pneumatic ureterolithotripsy in paediatric and adolescent patients: Aten-year experience at the Hospital University, Sains Malaysia. Singapore Med J 2011; 52:42-6.

[6] Satar N, Zeren S, Bayazit Y, Aridogan A, Soyupak B, Tansud Z. Rigid ureteroscopy for the treatment of ureteral calculi in children. $\mathrm{J}$ Urol.2004; 172:298-300.

[7] Jalbani MH. Minimally invasive approach for pediatric ureteric calculi.J Surg Pak2009;14:158.

[8] Iqbal N, Malik Y, Nadeem U, Khalid M, Pirzada A, Majeed Metal. Comparison of ureteroscopic pneumatic lithotripsy and extracorporeal shock wave lithotripsy for the management of proximal ureteral stones: A single center experience. Turk J Urol.201 8;44:221-227. doi: 10.5152 /tud.201 8.41848 . 
[9] Thomas DFM. Stone disease in children. In: Thomas DFM, Rickwood AMK, Duffy PG, editors. Essentials of pediatric urology. London:Martin Dunitz;2002: 113-23. 5.

[10] Ahmad I, Akhtar T, Ahmad B. Pediatric nephrolithiasis in Khyber Pakhtunkhwa Province, Pakistan. Pak J Med Sci 2012; 28:83 5-8.

[11] Rizvi SA, Naqvi SA, Hussain Z, Hashmi A, Hussain M, Zafar MN, et al. The management of stone disease. Br J Urol 2002; 89:62-8.

[12] Iqbal N, Assad S, Rahat Aleman Bhatti J, Hasan A, Shabbir MU, Akhter S. Comparison of Extracorporeal Shock Wave Lithotripsy for Urolithiasis between Children and Adults: A Single Centre Study. Cureus. 2016;29;8:e810.

[13] Tejwani R, Wang HS, Wolf S, Wiener JS, Routh JC. Outcomes of shock wave lithotripsy and ureteroscopy for treatment of pediatric urolithiasis. J Urol2016.

[14] Tan AH, Al-Omar M, Denstedt JD, Razvi H. Ureteroscopy for pediatric urolithiasis An evolving first-line therapy. Urology. 2005; 65:153-6.

[15] Ishii H, Griffin S, Somani BK. Ureteroscopy for stone disease in the paediatric population: Asystematic review. BJU Int2015; 115:867-73.

[16] Tan AH, Al-Omar M, Denstedt JD, Razvi H. Ureteroscopy for pediatric urolithiasis: An evolving first-line therapy. Urology. 2005; 65:153-6.

[17] Srivastava A, Dhayal IR, Rai P. Laparoscopic ureterolithotomy in children: With and without stent - Initial tertiary care center experience with more than 1-year follow-up. EurJ PediatrSurg 2016.

[18] Van Savage JG, Palanca LG, Andersen RD, Rao GS, Slaughenhoupt BL. Treatment of distal ureteral stones in children: Similarities to the American urological association guidelines in adults. J Urol. 2000;164:1089-93.

[19] Çitamak B, Mammadov E, Kahraman O, Ceylan T, Doğan HS, Tekgül S. SemiRigid Ureteroscopy Should Not Be the First Option for Proximal Ureteral Stones in Children. J Endourol. 2018:32:1028-1032.

[20] Schuster TG, Russell KY, Bloom DA, Koo HP, Faerber GJ. Ureteroscopy for the treatment of urolithiasis in children. J Urol. 2002; 167: 1813-6.

[21] Hussein NS, Gohar MR. Pneumatic ureterolithotripsy in paediatric and adolescent patients: Aten-year experience at the Hospital University, Sains Malaysia. Singapore Med J 2011; 52:42-6.

[22] Chedgy EC, Griffin SJ, Dyer JP, et al. Ureteroscopy for paediatric renal tract stones outcomes from atertiary European centre. Urol Int. 2015;95:320-3. doi:10.1159/000380857.

Citation: Nadeem Iqbal, et.al. Ureteroscopy in Children-A Single Centre Study from a Developing Country. ARC Journal of Urology.2019; 4(3): 7-11.doi:dx.doi.org/10.20431/2456-060X.0403002.

Copyright: (0) 2019 Authors. This is an open-access article distributed under the terms of the Creative Commons Attribution License, which permits unrestricted use, distribution, and reproduction in any medium, provided the original author and source are credited. 